\title{
Impact of objectively measured sedentary behaviour on changes in insulin resistance and secretion over three years: interaction with weight gain. The RISC Study.
}

\author{
E. Lahjibi ${ }^{\mathrm{a}, \mathrm{b}}$, B. Heude ${ }^{\mathrm{a}, \mathrm{b}}$, J.M. Dekker ${ }^{\mathrm{c}}$, K. Højlund ${ }^{\mathrm{d}, \mathrm{e}}$, M. Laville ${ }^{\mathrm{f}, \mathrm{g}}$, J. Nolan ${ }^{\mathrm{h}, \mathrm{i}}$, \\ J.-M. Oppert ${ }^{\mathrm{j}, \mathrm{k}, \mathrm{l}}$, B. Balkau, ${ }^{\mathrm{a}, \mathrm{b},{ }^{*}}$ for the RISC Study Group.
}

a INSERM CESP Centre for Research in Epidemiology and Population Health, U1018, Epidemiology of diabetes, obesity and chronic kidney disease over the life course, Villejuif, France

${ }^{b} \quad$ University Paris 11, UMRS 1018, Villejuif, France

c EMGO Institute for Health Care Research, Department of Epidemiology and Biostatistics, $V U$ University Medical Center, Amsterdam, The Netherlands

${ }^{d}$ Diabetes Research Centre, Department of Endocrinology, Odense University Hospital, Odense, Denmark

e Institute of Clinical Research, University of Southern Denmark, Odense, Denmark

$f$ CRNH Rhone-Alpes, Lyon University, INSERM U1060, CarMeN laboratory CENS,

$g$ Univ Lyon-1, Hospices Civils de Lyon, Service d'Endocrinologie, Diabétologie-Nutrition, F-69621 Lyon, France

h Steno Diabetes Center, Gentofte, Denmark

I Metabolic Research Unit, St James's Hospital, Trinity College, Dublin 8, Ireland

$j \quad$ Institute of Cardiometabolic Disease and Nutrition (ICAN), University Pierre et Marie Curie-Paris 6, Paris, France

${ }^{k}$ Department of Nutrition, Pitié-Salpetrière Hospital (AP-HP), CRNH IdF, Paris, France

$l$ Nutritional Epidemiology Unit, UMR INSERM U557/INRA U1125/CNAM/University Paris 13, CRNH IdF, Bobigny, France

The RISC Study group - see Supplementary Material

Word count Abstract: 249

Word count main text: 3407

2 tables, 1 figure

1 supplementary table, 1 supplementary figure

Running title: Sedentary behavior, insulin resistance and secretion changes

*Corresponding author:

Beverley Balkau,

INSERM U 1018 équipe 10,

CESP Centre for Research in Epidemiology and Population Health

16 Avenue Paul Vaillant Couturier, 94807 Villejuif cedex, France

tel: + 33145595161

fax: + 33147269454

E-mail: beverley.balkau@inserm.fr 


\section{Abstract}

Aims.-The importance of reducing sedentary-time is increasingly recognized for the prevention of diabetes and cardiovascular disease. Despite this, the prospective association between sedentary-time and physical activity with insulin sensitivity and cardio-metabolic risk factors has been little studied.

Methods.-We analyzed data from the European RISC study. Sedentary-time and time in activity of moderate or vigorous intensity were assessed by accelerometry at baseline in 313 men and 414 women, 30-60 years, with insulin sensitivity measured by euglycaemic hyperinsulinemic clamp. Three years later, cardio-metabolic risk factors (anthropometry, glucose, insulin, lipids) were available in 549 participants.

Results.-In cross-sectional analyses using baseline data, after adjusting for age, gender, recruitment centre and time in activity of moderate or vigorous intensity, significant unfavorable associations were observed between higher sedentary-time with body weight, HDL-cholesterol, triglycerides, clamp-measured insulin sensitivity and insulin secretion (all $\left.P_{\text {trend }}<0.002\right)$. Sedentary-time remained significantly associated with insulin secretion, after adjustment for insulin sensitivity $\left(P_{\text {trend }}=0.02\right)$. In longitudinal analyses, higher baseline sedentary-time was associated with 3-year increases in fasting glucose, fasting insulin and the HOMA insulin resistance index, for the $50 \%$ of our study population who increased their BMI by at least $0.3 \mathrm{~kg} / \mathrm{m}^{2}$ (all $P_{\text {trend }}<0.01$ ); these relations remained significant after adjusting for time spent in activity of moderate or vigorous intensity. The 3-year increase in insulin secretion was lower in those spending more time in activity of moderate or vigorous intensity $\left(P_{\text {trend }}=0.03\right)$.

Discussion.-This prospective data suggest that less sedentary behaviour, may counteract in part, some of the negative effects of increasing body weight on glucose-insulin homeostasis.

Keywords: cardio-metabolic risk, glucose, insulin, insulin resistance, physical activity, prospective, sedentary-time

Abbreviations: HOMA-IR: Homeostatic Model Assessment index of Insulin Resistance homeostasis 


\section{Impact d'un comportement sédentaire sur le changement de l'insulino-résistance et l'insulino-sécrétion sur trois ans : interaction avec le gain de poids L'étude RISC.}

Objectifs.-La limitation du temps consacré à des occupations sédentaires est de plus en plus prise en compte en matière de prévention du diabète et des maladies cardio-vasculaires. Cependant, l'association prospective entre comportements sédentaires et/ou l'activité physique et les facteurs de risque cardio-métaboliques est mal connue.

Matériel et méthodes.-Le temps sédentaire et la durée d'activité physique d'intensité modérée ou élevée ont été mesurés par accéléromètres chez 313 hommes et 414 femmes, âgés de 30 à 60 ans à l'inclusion dans l'étude européenne RISC. De façon concomitante, l'insulino-sensitibilité a été quantifiée par clamp euglycémique hyperinsulinémique. Après trois ans, les facteurs de risque cardio-métaboliques (anthropométrie, glycémie, insulinémie, lipides) ont été remesurés et étaient analysables chez 549 participants de l'étude.

Résultats.-Les analyses transversales à l'inclusion, après ajustement sur l'âge, le sexe, le centre de recrutement et la durée d'activité physique d'intensité modérée ou élevée, montraient des associations défavorables entre le temps sédentaire et le poids corporel, le cholestérol-HDL, les triglycérides, l'insulino-sensibilité (mesuré par le clamp) et l'insulinosécrétion (tous $P_{\text {tendance }}<0.002$ ). L'association entre le temps sédentaire et l'insulino-sécrétion restait significative après ajustement pour l'insulino-sensibilité $\left(P_{\text {tendance }}=0.02\right)$. Les analyses longitudinales montraient que plus de temps passé sédentaire était élevé, plus la glycémie et l'insulinémie à jeun et l'indice HOMA d'insulino-résistance étaient augmentés, mais ceci uniquement chez les individus dont l'IMC augmentait: (de plus de $0.3 \mathrm{~kg} / \mathrm{m}^{2}$, médiane de sa variation sur 3 ans) (tous $P_{\text {tendance }}<0.01$ ); ces associations restaient significatives après ajustement additionnel sur la durée des activités physiques d'intensité modérée ou élevée. La variation sur 3 ans de l'insulino-secretion était plus bas chez ceux qui passaient plus de temps dans les activities physique d'intensité modérée ou élevée $\left(P_{\text {trend }}=0.03\right)$.

Conclusions.-Les données de cette étude prospective suggèrent qu'une limitation du temps consacré aux occupations sédentaires pourrait compenser, au moins en partie, les effets négatifs d'une augmentation de poids sur l'homéostasie glucidique.

Mots clés : activité physique, comportement sédentaire, glycémie, insulinémie, insulinorésistance, prospective, risque cardio-métabolique 


\section{Introduction}

In addition to the well-established role of physical activity for prevention of chronic diseases such as type 2 diabetes [1,2], the deleterious impact of sedentary-time is increasingly documented $[3,4]$. In longitudinal studies, mortality and morbidity have been associated with sedentary behaviours, such as television viewing [5,6], but this is only part of the time spent sedentary [7]. In developed countries, more than 50\% of waking time, as measured by accelerometry, is sedentary [8-11]. Sedentary-time as recorded by questionnaire is lower, and depends not only on the validity and reliability of questionnaires [12] but also on the questions asked and the definitions used. In European countries, the prevalence of sedentarytime, as evaluated by the International Physical Activity Questionnaire (IPAQ) and defined as less than 3,000 MET minutes per week accumulated over seven days, ranged from $19 \%$ to $43 \% ; 23 \%$ to $56 \%$ of people spent $>6$ hours per day sitting [13]. Thus in western societies, a very large percentage of waking time is spent sedentary.

While the relations between sedentary-time and morbidity and mortality have been extensively studied [3-6], we have identified only three prospective studies with objectively measured sedentary-time that investigated its impact on changes in cardio-metabolic risk $[10,14,15]$. Changes in cardio-metabolic risk factors have been studied in relation with physical activity documented objectively [16] and by questionnaire [17-22].

In contrast, cross-sectional studies have evaluated sedentary-time and cardiometabolic risk factors, with sedentary-time evaluated objectively by accelerometry $[9,11,23]$, and by questionnaire [24-26]. We have already shown that insulin sensitivity is related with total activity, the intensity of activity and with sedentary-time, using cross-sectional data from the Relationship between Insulin Sensitivity and Cardiovascular disease (RISC) Study, where activity was evaluated by an accelerometer [8].

This report studies the 3-year evolution of cardio-metabolic risk factors with sedentary-time, in participants from the RISC Study [27]. In parallel we study associations with time spent in activities of moderate or vigorous intensity. 


\section{Research Design and Methods}

RISC is a 3-year observational cohort study aiming to evaluate insulin resistance and atherosclerosis development [27]; in 2002-2004, > 1,400 volunteers were recruited in 20 centres in 13 European countries, aged 30-60 years, without diabetes, hypertension, or dyslipidaemia. Each recruitment centre had ethics committee approval for the study, and participants gave written informed consent. Examinations included anthropometry, blood pressure, blood sampling, oral glucose tolerance test (blood drawn at fasting, 30, 60, 90 and 120 mins), euglycaemic hyperinsulinaemic clamp. Activity and sedentary behaviours were monitored in participants who consented to wear an accelerometer. All above examinations, except for the euglycaemic hyperinsulinaemic clamp and accelerometer monitoring, were repeated after three years.

\section{Study Population}

At baseline, among 1259 volunteers with an evaluation of insulin sensitivity, 847 had data on physical activity recorded by accelerometry, 777 satisfied study entry criteria, and 727 had data on cardio-metabolic parameters. At three years, anthropometry, blood pressure and plasma sample data were available for 549 participants.

\section{Methods of measurement of cardio-metabolic risk factors}

Body weight and body composition (fat-free-mass, fat-mass) were measured by bipedal bioelectric impedance analysis (TBF300; TANITA International Division, UK) on lightly clad participants, height with a clinical stadiometer, waist circumference by tapemeasure horizontally placed mid-way between the lower costal margins and iliac crests on the midaxillary line; body-fat $(\%)=100 *($ fat-mass $(\mathrm{kg})) /$ body-weight $(\mathrm{kg}))$. Sitting systolic and diastolic blood pressures were measured three times by an automated device (OMRON 705cp, OMRON Healthcare Europe, Netherlands) and the median used in analyses.

Biology was assayed centrally [27]. In Odense, Denmark, plasma glucose was measured by the glucose oxidase technique (Cobas Integra; Roche), and serum insulin by a specific time-resolved fluoroimmunoassay (AutoDELFIA Insulin kit; Wallac Oy, Turku, Finland). In Dublin, Ireland, total-cholesterol, HDL-cholesterol and triglycerides were measured using colorimetric enzymatic tests (respectively, Roche Cholesterol Method for Modular Systems, Roche HDL $2^{\text {nd }}$ Generation Method for Modular Systems, and Roche Triglycerides Method for Modular System). LDL-cholesterol concentration was calculated by the Friedewald formula. 
At baseline the hyperinsulinaemic euglycaemic clamp quantified insulin sensitivity [27]. The Homeostatic Model Assessment index of insulin resistance HOMA-IR was calculated at baseline and three years [28].

Insulin secretion has been quantified at baseline and at three years by:

Insulin secretion index $=($ insulin $30 \mathrm{~min}-$ insulin $0 \mathrm{~min}) /($ glucose $30 \mathrm{~min})$ [29] .

Physical activity and sedentary-time were measured objectively by a small single-axis accelerometer (Actigraph, AM7164-2.2; Computer Science and Applications, Pensacola, FL) [30]. Acceleration signals were digitized by an 8-bit analog to digital converter, sampling 10 times per second. Each digitized signal was summed over a 1-minute interval and total activity (counts per minute) was saved in memory. The accelerometer was secured by a belt at the small of the back from waking until going to sleep, except during water-based activities, and it was worn for up to eight days. We included only those days when the accelerometer was worn for at least 10 hours and only those people with at least three days of recording. Non-wearing periods were identified as 60 minutes or more of continuous zero counts. Accelerometer data were processed with custom software developed for this project using SAS version $9.1[8]$.

Cut-offs were used to define sedentary behavior ( $<100$ counts/min), and activities of moderate or vigorous intensity (1952 to 5724 counts/min, and >5724 counts/min, respectively) [30,31]. For activity of moderate or vigorous intensity, >10 minutes was required, according to recommendations of "bouts lasting 10 minutes or more" [1].

Two parameters are analyzed in this report:

- sedentary-time, the time when participants were sedentary;

- time spent in activities of moderate or vigorous intensity.

\section{Statistical Analyses}

Analyses used SAS (version 9.2). Variables with non-symmetric distributions: triglycerides, insulin, insulin sensitivity, HOMA-IR, and the insulin secretion index, were logarithmically transformed. Participant characteristics, at baseline and follow-up, are described by means (SD), geometric means $(\mathrm{x} / \div \exp [\mathrm{SD} \log$-transformed data]) or $\mathrm{n}(\%)$, and compared between men and women, or between those followed at three years and those not followed, using ttests, $\chi^{2}$ tests and for the activity variables, Wilcoxon tests. Spearman correlation coefficients were calculated. Linear models were used to study both cross-sectional associations and the three-year evolution of cardio-metabolic risk factors, in relation with activity variables measured at baseline; models were adjusted for age, gender and for recruitment centre 
(included in models as a random factor). Data from men and women were combined as there were very few interactions between gender and activity variables; gender specific results are presented where there was a significant interaction.

To correct for the time that the accelerometer was worn, we analysed residuals from sexspecific models with time variables regressed on the time the accelerometer was worn $[23,32]$. We have not analysed time spent in light intensity activity (time not sedentary nor in activity of moderate or vigorous intensity) as it was highly correlated with sedentary-time $\left(\mathrm{r}_{\text {Spearman }}=-\right.$ $0.95,-0.98$ in men and women respectively).

Sedentary-time and time spent in activity of moderate or vigorous intensity were analyzed in sex-specific quartile groups, and $P_{\text {trend }}$ across quartile groups is presented. As $31 \%$ of men and $34 \%$ of women had no activity of moderate or vigorous intensity, this variable and sedentary-time are analyzed in classes. In a sensitivity analysis, sedentary-time was analyzed as a continuous variable.

Cross-sectional associations with sedentary-time were further adjusted for time spent in activities of moderate or vigorous intensity, and associations with time spent in activity of moderate or vigorous intensity were further adjusted for BMI.

The three-year evolution of all cardio-metabolic risk factors was analysed according to baseline sedentary-time and time spent in activities of moderate or vigorous intensity. Interactions were sought between sedentary-time and factors which could modify the effect of sedentary time: baseline insulin sensitivity, baseline BMI and three-year change in BMI. These three factors were divided according to their medians. Significant interactions were only observed $(P<0.05)$ between change in BMI (median $\left.=+0.3 \mathrm{~kg} / \mathrm{m}^{2}\right)$ and cardio-metabolic risk factor evolution. Sedentary-time analyses were further adjusted on time spent at baseline in activities of moderate or vigorous intensity.

\section{Results}

\section{Population description}

The mean age at baseline of the 313 men and 414 women was 43 and 45 years, with mean BMI 25.8 and $24.3 \mathrm{~kg} / \mathrm{m}^{2}$, respectively (Table 1). Gender differences were observed for most of the body composition and metabolic variables, and men generally had a more at-risk profile than women. In our study population, more than $60 \%$ of accelerometer wearing time was spent sedentary, and on average, men spent more hours sedentary than women $(P=0.0007)$. Men spent marginally more time in activities of moderate or vigorous intensity than women $(P=0.12)$. Sedentary-time and time spent in activities of moderate or vigorous 
intensity, both adjusted for the time the accelerometer was worn, were correlated, with Spearman correlation coefficients $\mathrm{r}=-0.15$ for men and $\mathrm{r}=-0.25$ for women (both $P<0.007$ ).

The participants who were followed up at three years, were older than those who did not participate ( 45 vs 41 years, $P=0.0001$ ), but there were no differences in other baseline variables after age adjustment.

Cross-sectional analysis of sedentary-time and physical activity with cardio-metabolic risk factors at baseline

Sedentary-time was positively associated with body weight (but not with BMI or body fat), waist circumference, triglycerides, insulin secretion, and negatively associated with insulin sensitivity (as measured by the clamp) and HDL-cholesterol, after adjustment for age, gender and recruitment centre (all $P_{\text {trend }}<0.04$ ) (Table 2); these relations were attenuated but all remained statistically significant after adjustment for the time spent in activities of moderate or vigorous intensity, excepting for waist circumference $\left(P_{\text {trend }}=0.12\right)$. The insulin secretion index increased with sedentary-time, and remained significant after additional adjustment for clamp measured insulin sensitivity $\left(P_{\text {trend }}=0.02\right)$.

When sedentary-time was analyzed as a continuous variable rather than in quartiles, the relations for higher body weight, triglycerides, insulin secretion, insulin sensitivity, and lower HDL-cholesterol, remained significant; further, LDL-cholesterol and $2 \mathrm{~h}$-insulin were positively and significantly related with sedentary-time $\left(P_{\text {trend }}=0.04,0.008\right.$ respectively) and fasting glucose and fasting insulin both showed a marginal significance $\left(P_{\text {trend }}=0.056,0.054\right.$ respectively); waist circumference also showed a marginal association $\left(P_{\text {trend }}=0.13\right)$.

Supplementary Table 1 shows mean values of cardio-metabolic parameters according to quartiles of time spent in activities of moderate or vigorous intensity. The anthropometric measures were strongly related with the time spent in these activities (all $P_{\text {trend }}<0.0001$ ), and waist circumference remained associated after adjustment for BMI. Blood pressure, heart rate; lipids, insulin and insulin sensitivity measured both by the clamp and by the HOMA-IR index as well as insulin secretion were associated with the time spent in activities of moderate or vigorous intensity (all $P_{\text {trend }}<0.05$ ); glucose concentrations were not associated with these activities. After adjusting for BMI, more time spent in activities of moderate or vigorous intensity was associated with lower waist circumference, heart rate, total and LDLcholesterol, fasting insulin and higher HDL-cholesterol concentrations. The favorable relations seen with blood pressure, triglycerides, insulin sensitivity and insulin secretion were no longer significant after accounting for BMI. 
Prospective analysis of sedentary-time and physical activity with the evolution of cardiometabolic risk factors

There were no relations between sedentary time or time in activities of moderate or vigorous intensity and changes in cardio-metabolic risk factors, and there were no effect modifications with baseline BMI or insulin sensitivity, as interactions were all non-significant. However for the 3-year change in BMI, there were significant interactions for both activity variables, with fasting glucose, fasting insulin and HOMA-IR. In the 50\% of participants who had an increase in BMI of at least $0.3 \mathrm{~kg} / \mathrm{m}^{2}$, (median BMI change), baseline sedentary-time and the time in activities of moderate or vigorous intensity, were associated with the evolutions in fasting glucose, fasting insulin and HOMA-IR (Fig. 1, Supplementary Fig. 1): people with sedentary time below the lower quartile had a $0.2 \mathrm{mmol} / \mathrm{l}$ lower 3 -year change in fasting glucose than those above the upper quartile. These three relations with baseline sedentary-time remained significant after controlling for time spent in activities of moderate or vigorous intensity (all $P_{\text {trend }}<0.05$ ).

The only other significant association was a smaller 3-year change in insulin secretion in those with more time spent in moderate or vigorous activity at baseline $\left(P_{\text {trend }}=0.03\right.$, with mean insulin secretion indices in the four quartile groups: 17.8, 14.4, 16.3, and 12.6 respectively). This association remained significant after adjusting for the 3-year change in the HOMA-IR index $\left(P_{\text {trend }}=0.05\right)$, but lost significance when adjusted for baseline insulin clamp-evaluated insulin sensitivity $\left(P_{\text {trend }}=0.55\right)$. There was no interaction with the 3-year change in $\operatorname{BMI}(P=0.15)$.

At baseline, there were no significant differences in the characteristics of those who increased their BMI by at least $0.3 \mathrm{~kg} / \mathrm{m}^{2}$, and those who did not. The factor that differed most between these two groups was insulin sensitivity, with geometric means of 134 and $144 \mu \mathrm{mol} \cdot \mathrm{min}^{-1} \cdot \mathrm{kg}_{\mathrm{FFM}}{ }^{-1} \cdot \mathrm{nmol} / \mathrm{I}^{-1}$ respectively $(P=0.066)$

Changes in other cardio-metabolic parameters, (BMI, waist circumference, blood pressure, heart rate, total, HDL- and LDL-cholesterol, triglycerides, the post charge values of glucose and insulin) were not significantly related with sedentary-time, nor with the time spent in activities of moderate or vigorous intensity. 


\section{Discussion}

Less sedentary-time and more time in activities of moderate or vigorous intensity at baseline were associated with smaller increases in fasting glucose, fasting insulin and insulin resistance over the 3-year period, but only in those who increased more their BMI.

In cross-sectional analyses, the time in activities of moderate or vigorous intensity was associated with lower values of the anthropometric variables, whereas sedentary-time was associated only with a higher body weight, after adjusting for time in activities of moderate or vigorous intensity. Sedentary-time was also associated with higher triglycerides, insulin sensitivity and secretion and lower HDL-cholesterol, after adjusting for time spent in activities of moderate or vigorous intensity. Insulin secretion was still related with sedentarytime after additionally adjusting on clamp-measured insulin sensitivity. For participants who spent more time in activities of moderate or vigorous intensity, after BMI adjustment, lower mean values were recorded for waist circumference, heart rate, total, LDL-cholesterol and fasting insulin and higher means for HDL-cholesterol.

Cross sectional relations between cardio-metabolic risk factors and objectively measured sedentary-time

Our cross-sectional results can be compared with studies on sedentary behaviour assessed using accelerometry $[9,11,15,23]$. Of note none of these studies assessed insulin sensitivity by the gold-standard clamp method. After accounting for physical activity, a small Australian study found that waist, only, was related with sedentary-time [9]; one study in the NHANES population showed no relation with the metabolic syndrome [11], yet another analysis on a larger NHANES population showed relations with waist circumference, HDLcholesterol, triglycerides, insulin, HOMA-IR and the HOMA insulin-secretion index [15]; in a study of newly-diagnosed type 2 diabetic patients, associations were found with waist circumference, HDL cholesterol, insulin and the HOMA-IR index [23].

In our study, body weight (but not BMI nor waist circumference), HDL-cholesterol, triglycerides, clamp measured insulin sensitivity (but not HOMA-IR) and insulin secretion were all associated with sedentary-time, after adjusting for the time spent in activities of moderate or vigorous intensity. These results are in line with other studies, and show the advantages of the more precise clamp measure of insulin sensitivity over the HOMA-IR index, which was not significantly associated with sedentary-time in the RISC data. Furthermore insulin secretion remained associated with sedentary-time after adjustment for clamp measured insulin sensitivity. Both insulin sensitivity and insulin secretion are key 
elements in the progression towards type 2 diabetes, and this association with sedentary-time provides a rationale for targeting sedentary behavior in diabetes prevention programs.

Prospective relations between changes in cardio-metabolic risk factors and objectively evaluated sedentary-time

In the Ely study, sedentary-time was measured objectively by heart rate monitoring and insulin sensitivity was evaluated by both fasting plasma insulin and the HOMA-IR index in 166 men and 210 women followed 5.6 years [10]. Percent time sedentary and percent time spent in activities of moderate or vigorous intensity were significantly associated with fasting insulin concentrations, but only sedentary-time remained associated after adjustment for covariates, in particular baseline fasting insulin.

In the ProActive trial [14], 81 men and 111 women with a family history of diabetes were followed over one year. Physical activity was measured by accelerometery. The HOMAIR index and fasting insulin at follow up were only associated with time spent in activities of moderate or vigorous intensity but not with sedentary-time.

The Early Activity in Diabetes study [15], after a follow-up of six months, showed a significant relation between sedentary-time and HDL-cholesterol, even after adjustment for waist circumference $(P=0.003)$ and there were marginal relations with waist circumference, insulin and the HOMA-IR index (all $P<0.1$ ); the latter two relations were greatly attenuated after adjustment on waist circumference.

In our study, we found a relation between change in the HOMA-IR index, as well as for fasting glucose and insulin, with sedentary-time and with the time spent in activities of moderate or vigorous intensity - but only in the half of the population gaining more weight over follow-up. Body weight gain over time is recognized as a risk factor for type 2 diabetes [33-35] and cardiovascular disease [36], and our results show that less sedentary-time and more activity can influence glucose homeostasis. The data reinforce the notion that efforts should be directed at limiting time spent in sedentary behavior for maintenance of metabolic health over time, independently of physical activity, even though there was no association with changes in lipids or blood pressure.

The 3-year change in insulin secretion was lower in those who spent more time in activities of moderate or vigorous intensity - but as might be expected, this relation was no longer significant after adjusting on the baseline clamp-based insulin sensitivity, because their higher insulin sensitivity required less insulin secretion. 


\section{Study strengths and limitations}

To our knowledge, this is the first study to report on associations between objectively measured sedentary-time and its relation with changes in cardio-metabolic risk factors. We were also able to evaluate insulin sensitivity and insulin secretion.

One of the disadvantages of using accelerometry is that we do not know when people are not wearing the accelerometer, and we and others have defined non-wearing periods by an arbitrary period of continuous zero counts. Thus, the sedentary-time may be over-evaluated as the accelerometer was not being worn, and conversely, excluded time may be very long periods of sedentary-time.

We were not able to follow-up our entire baseline population, however the baseline characteristics of participants studied at three years were similar to those not studied.

A further limitation is that we did not have a second accelerometer recording to evaluate changes in activity over the three years, but from the International Physical Activity Questionnaire (IPAQ) $[13,37]$ there was little change in total activity in our study population, with a mean total MET-minutes per week increase of $5 \%(P=0.2)$.

Our definition of moderate and vigorous activity required bouts of 10 minutes of such activities, in accord with recommendations [1]. When we adjusted the prospective relations with sedentary time for total physical activity at baseline, the results were attenuated, and remained significant only for the change in fasting glucose.

\section{Conclusions}

As summarized by Tremblay [3] "sedentary behaviour, as distinct from lack of moderate to vigorous physical activity, has independent and qualitatively different effects on human metabolism, physical function, and health outcomes and thus should be treated as a separate and unique construct". In experimental work, sedentary-time has been associated with higher lipids (partly mediated by lipoprotein lipase activity) [37], higher glucose and insulin resistance (perhaps mediated by muscle glucose transporter (GLUT4) protein content) [38].

In the RISC free-living population, more than $60 \%$ of time was spent sedentary, and less than $1 \%$ of time in activity of moderate or vigorous intensity - the remaining time was spent in "light activities", which contribute to the total daily physical activity. While recommendations to increase activity with moderate intensity activities such as walking are important, the promotion of less sedentary behaviour and more light activity is also important. 
Indeed, the changes in fasting glucose, insulin and the HOMA-IR index were all attenuated after adjusting for total activity, but not for activity of a moderate or vigorous intensity.

The relations we and others have observed are not strong, and the parameters shown to have effects have not always been consistent between studies. However, changing the level of activity may have an impact on metabolic health if intervention can induce a population shift to less sedentary-time. Indeed two recent reviews propose that high quality prospective studies using device based measures may provide a better understanding of the impact of sedentary-time on health outcomes $[39,40]$.

In conclusion, these results suggest that less sedentary behaviour and more activities of moderate or vigorous intensity may partly counteract some of the negative effects of increasing body weight on glucose homeostasis over time. These findings may help target at risk groups in health policies aiming to prevent diabetes at the population level.

\section{Author contributions}

EL and BB carried out the statistical analyses and wrote the article; BH and JMO provided advice during these two stages; JMD, KH, ML, JJN recruited participants and provided input to the final version of the article.

The authors have no conflict of interest in regard to this paper.

For the complete list of RISC investigators, please see XXXXXXXXXXXXXXXXXXX

Acknowledgements : The RISC Study was supported by EU grant QLG1-CT-2001-01252, with additional support from AstraZeneca (Sweden). The EGIR group activities are supported by an unrestricted research grant from Merck Serono, France.

E Lahjibi received financial support with a research grant from the Société Francophone du Diabète, financed by Abbott. 


\section{References}

[1] Haskell WL, Lee IM, Pate RR, Powell KE, Blair SN, Franklin BA, et al.; American College of Sports Medicine; American Heart Association. Physical activity and public health: updated recommendation for adults from the American College of Sports Medicine and the American Heart Association. Circulation 2007;116:1081-93.

[2] O'Donovan G, Blazevich AJ, Boreham C, Cooper AR, Crank H, Ekelund U, et al. The ABC of Physical Activity for Health: a consensus statement from the British Association of Sport and Exercise Sciences. J Sports Sci 2010;28:573-91.

[3] Tremblay MS, Colley RC, Saunders TJ, Healy GN, Owen N. Physiological and health implications of a sedentary lifestyle. Appl Physiol Nutr Metab 2010;35:725-40.

[4] Owen N, Bauman A, Brown W. Too much sitting: a novel and important predictor of chronic disease risk? Br J Sports Med 2009;43:81-3.

[5] Dunstan DW, Barr EL, Healy GN, Salmon J, Shaw JE, Balkau B, et al. Television viewing time and mortality: the Australian Diabetes, Obesity and Lifestyle Study (AusDiab). Circulation 2010;121:384-91.

[6] Wijndaele K, Brage S, Besson H Khaw KT, Sharp SJ, Luben R, et al. Television viewing and incident cardiovascular disease: prospective associations and mediation analysis in the EPIC Norfolk Study. PLoS One 2011;6:e20058

[7] Biddle SJ (2007) Sedentary behavior. Am J Prev Med 2007;33:502-4.

[8] Balkau B, Mhamdi L, Oppert JM, Nolan J, Golay A, Porcellati F, et al.; EGIR-RISC Study Group. Physical activity and insulin sensitivity: the RISC study. Diabetes 2008;57:2613-8.

[9] Healy GN, Wijndaele K, Dunstan DW, Shaw JE, Salmon J, Zimmet PZ, et al. Objectively measured sedentary time, physical activity, and metabolic risk: the Australian Diabetes, Obesity and Lifestyle Study (AusDiab). Diabetes Care 2008;31:369-71.

[10] Helmerhorst HJ, Wijndaele K, Brage S, Wareham NJ, Ekelund U. Objectively measured sedentary time may predict insulin resistance independent of moderate- and vigorousintensity physical activity. Diabetes 2009;58:1776-9.

[11] Bankoski A, Harris TB, McClain JJ , Brychta RJ, Caserotti P, Chen KY, et al. Sedentary activity associated with metabolic syndrome independent of physical activity. Diabetes Care 2011;34:497-503.

[12] Shephard RJ. Limits to the measurement of habitual physical activity by questionnaires. Br J Sports Med. 2003;37:197-206. 
[13] Sjöström M, Oja P, Hagströmer M, Smith BJ, Bauman A. Health-enhancing physical activity across European Union countries: the Eurobarometer study. J Public Health 2006;14:291-300.

[14] Ekelund U, Brage S, Griffin SJ, Wareham NJ; ProActive UK Research Group. Objectively measured moderate- and vigorous-intensity physical activity but not sedentary time predicts insulin resistance in high-risk individuals. Diabetes Care 2009;32:1081-6.

[15] Cooper AR, Sebire S, Montgomery AA, Peters TJ, Sharp DJ, Jackson N, et al. Sedentary time, breaks in sedentary time and metabolic variables in people with newly diagnosed type 2 diabetes. Diabetologia 2012;55:589-99.

[16] Simmons RK, Griffin SJ, Steele R, Wareham NJ, Ekelund U; ProActive Research Team. Increasing overall physical activity and aerobic fitness is associated with improvements in metabolic risk: cohort analysis of the ProActive trial. Diabetologia 2008;51:787-94.

[17] Byberg L, Zethelius B, McKeigue PM, Lithell HO. Changes in physical activity are associated with changes in metabolic cardiovascular risk factors. Diabetologia 2001;44:2134-9.

[18] Laaksonen DE, Lakka HM, Salonen JT, Niskanen LK, Rauramaa R, Lakka TA. Low levels of leisure-time physical activity and cardiorespiratory fitness predict development of the metabolic syndrome. Diabetes Care 2002;25:1612-8.

[19] Hernelahti M, Kujala U, Kaprio J. Stability and change of volume and intensity of physical activity as predictors of hypertension. Scand J Public Health 2004; 32:303-9.

[20] Balkau B, Vierron E, Vernay M, Born C, Arondel D, Petrella A, et al.; D.E.S.I.R Study Group. The impact of 3-year changes in lifestyle habits on metabolic syndrome parameters: the D.E.S.I.R study. Eur J Cardiovasc Prev Rehabil 2006;13:334-40.

[21] Yang X, Telama R, Hirvensalo M. The longitudinal effects of physical activity history on metabolic syndrome. Med Sci Sports Exerc 2008;40:1424-31.

[22] Cheriyath P, Duan Y, Qian Z, Nambiar L, Liao D. Obesity, physical activity and the development of metabolic syndrome: the Atherosclerosis Risk in Communities study. Eur J Cardiovasc Prev Rehabil 2010;17:309-13.

[23] Healy GN, Matthews CE, Dunstan DW, Winkler EA, Owen N. Sedentary time and cardio-metabolic biomarkers in US adults: NHANES 2003-06. Eur Heart J 2011;32:590-7.

[24] Bertrais S, Beyeme-Ondoua JP, Czernichow S, Galan P, Hercberg S, Oppert JM. Sedentary behaviors, physical activity, and metabolic syndrome in middle-aged French 
subjects. Obes Res 2005;13:936-44.

[25] Thorp AA, Healy GN, Owen N. Deleterious associations of sitting time and television viewing time with cardiometabolic risk biomarkers: Australian Diabetes, Obesity and Lifestyle (AusDiab) study 2004-2005. Diabetes Care 2010;33:327-34.

[26] Stamatakis E, Hamer M. The extent to which adiposity markers explain the association between sedentary behavior and cardiometabolic risk factors. Obesity 2012;20:229-32.

[27] Hills SA, Balkau B, Coppack SW, Dekker JM, Mari A, Natali A, et al.; EGIR-RISC Study Group The EGIR-RISC STUDY (The European group for the study of insulin resistance: relationship between insulin sensitivity and cardiovascular disease risk): I. Methodology and objectives. Diabetologia 2004;47:566-70.

[28] Matthews DR, Hosker JP, Rudenski AS, Naylor BA, Treacher DF, Turner RC. Homeostasis model assessment: insulin resistance and beta-cell function from fasting plasma glucose and insulin concentrations in man. Diabetologia 1985;28:412-9.

[29] Wareham NJ, Phillips DI, Byrne CD, Hales CN. The 30 minute insulin incremental response in an oral glucose tolerance test as a measure of insulin secretion. Diabet Med $1995 ; 12: 931$.

[30] Freedson PS, Melanson E, Sirard J. Calibration of the Computer Science and Applications, Inc. accelerometer. Med Sci Sports Exerc 1998;30:777-81.

[31] Ekelund U, Griffin SJ, Wareham NJ. Physical activity and metabolic risk in individuals with a family history of type 2 diabetes. Diabetes Care 2007;30:337-42.

[32] Willett W, Stampfer MJ. Total energy intake: implications for epidemiologic analyses. Am J Epidemiol 1986;124:17-27.

[33] Colditz GA, Willett WC, Rotnitzky A, Manson JE. Weight gain as a risk factor for clinical diabetes mellitus in women. Ann Intern Med 1995;122:481-6.

[34] Hanson RL, Narayan KM, McCance DR, Pettitt DJ, Jacobsson LT, et al. Rate of weight gain, weight fluctuation, and incidence of NIDDM. Diabetes 1995;44: 261-6.

[35] Wannamethee SG, Shaper AG, Walker M. Overweight and obesity and weight change in middle aged men: impact on cardiovascular disease and diabetes. J Epidemiol Community Health 2005; 59: 134-9.

[36] Willett WC, Manson JE, Stampfer MJ, Colditz GA, Rosner B, Speizer FE, et al. Weight, weight change, and coronary heart disease in women. Risk within the 'normal' weight range. JAMA 1995;273:461-5.

[37] Zderic TW, Hamilton MT. Physical inactivity amplifies the sensitivity of skeletal muscle to the lipid-induced downregulation of lipoprotein lipase activity. J Appl Physiol 
2006;100:249-57.

[38] Klip A, Pâquet MR. Glucose transport and glucose transporters in muscle and their metabolic regulation. Diabetes Care 1990;13:228-43.

[39] Thorp AA, Owen N, Neuhaus M, Dunstan DW. Sedentary behaviors and subsequent health outcomes in adults a systematic review of longitudinal studies, 1996-2011. Am J Prev Med 2011;41:207-15.

[40] Proper KI, Singh AS, van Mechelen W, Chinapaw MJ. Sedentary behaviors and health outcomes among adults: a systematic review of prospective studies. Am J Prev Med 2011;40:174-82. 


\section{FIGURE LEGEND}

Fig. 1 Mean (SE) of 3-year changes in (a) fasting glucose, (b) fasting insulin and (c) the HOMA-IR index according to baseline sedentary-time, adjusted for age, gender and clinical recruitment centre, according to strata of change in BMI below and above the median change of $+0.3 \mathrm{~kg} / \mathrm{m}^{2}$. The RISC study 


\section{Table 1}

Anthropometric and metabolic characteristics and accelerometer measures of activity: the RISC study

\begin{tabular}{|c|c|c|c|}
\hline & Men $(n=313)$ & Women $(n=414)$ & $P$-value ${ }^{c}$ \\
\hline Age (years) & $43 \pm 9$ & $45 \pm 8$ & 0.02 \\
\hline Body weight (kg) & $82 \pm 12$ & $66 \pm 12$ & $<0.0001$ \\
\hline $\operatorname{BMI}\left(\mathrm{kg} / \mathrm{m}^{2}\right)$ & $25.8 \pm 3.1$ & $24.3 \pm 4.0$ & $<0.0001$ \\
\hline Body fat $(\%)$ & $21 \pm 6$ & $32 \pm 7$ & $<0.0001$ \\
\hline Waist circumference $(\mathrm{cm})$ & $92 \pm 10$ & $80 \pm 11$ & $<0.0001$ \\
\hline Systolic BP (mmHg) & $122 \pm 10$ & $113 \pm 12$ & $<0.0001$ \\
\hline Diastolic BP (mmHg) & $76 \pm 7$ & $73 \pm 8$ & $<0.0001$ \\
\hline Heart rate (beats/min) & $64 \pm 9$ & $69 \pm 11$ & $<0.0001$ \\
\hline Total cholesterol (mmol/l) & $4.88 \pm 0.85$ & $4.78 \pm 0.85$ & 0.10 \\
\hline HDL-cholesterol (mmol/l) & $1.28 \pm 0.28$ & $1.61 \pm 0.40$ & $<0.0001$ \\
\hline LDL-cholesterol (mmol/l) & $3.07 \pm 0.77$ & $2.73 \pm 0.78$ & $<0.0001$ \\
\hline Triglycerides $(\mathrm{mmol} / \mathrm{l})^{\mathrm{a}}$ & $1.05 \times / \div 1.57$ & $0.85 \mathrm{x} / \div 1.56$ & $<0.0001$ \\
\hline Fasting glucose $(\mathrm{mmol} / \mathrm{l})$ & $5.2 \pm 0.5$ & $5.0 \pm 0.5$ & $<0.0001$ \\
\hline 2h-glucose (mmol/l) & $5.6 \pm 1.5$ & $5.8 \pm 1.5$ & 0.06 \\
\hline Fasting insulin $(\mathrm{pmol} / \mathrm{l})^{\mathrm{a}}$ & $30 \mathrm{x} / \div 1.67$ & $28 \times / \div 1.69$ & 0.12 \\
\hline 2h-insulin $(\mathrm{pmol} / \mathrm{l})^{\mathrm{a}}$ & $114 \mathrm{x} / \div 2.46$ & $155 \mathrm{x} / \div 2.05$ & $<0.0001$ \\
\hline $\begin{array}{l}\text { Insulin sensitivity } \\
\qquad\left(\mu \mathrm{mol} \cdot \mathrm{min}^{-1} \cdot \mathrm{kg}_{\mathrm{FFM}}{ }^{-1} \cdot \mathrm{nmol} / \mathrm{l}^{-1}\right)^{\mathrm{a}}\end{array}$ & $121 \mathrm{x} / \div 1.63$ & $149 \mathrm{x} / \div 1.50$ & $<0.0001$ \\
\hline HOMA-IR ${ }^{a}$ & $6.92 \times / \div 1.73$ & $6.23 \times / \div 1.78$ & 0.01 \\
\hline Insulin secretion index ${ }^{a}$ & $25 \mathrm{x} / \div 1.87$ & $25 \mathrm{x} / \div 1.92$ & 0.64 \\
\hline \multicolumn{4}{|l|}{ ACCELEROMETER } \\
\hline Number of days accelerometer worn & $6(5,7)$ & $6(5,7)$ & 0.94 \\
\hline Wearing time (hours) & $92(72,105)$ & $87(70-103)$ & 0.06 \\
\hline Sedentary-time (hours) ${ }^{b}$ & $55(41,64)$ & $50(39-60)$ & 0.0007 \\
\hline Percent time & $62 \%$ & $59 \%$ & \\
\hline $\begin{array}{r}\text { Moderate or vigorous intensity activity } \\
\text { (hours) }\end{array}$ & $0.6(0.0-1.8)$ & $0.4(0.0,1.4)$ & 0.12 \\
\hline Percent time & $1 \%$ & $1 \%$ & \\
\hline $\begin{array}{l}\text { No moderate or vigorous intensity } \\
\text { activity, but not sedentary (hours) }\end{array}$ & $30(22,39)$ & $34(25,41)$ & 0.02 \\
\hline Percent time & $37 \%$ & $40 \%$ & \\
\hline
\end{tabular}

Data shown are $n(\%)$, means $\pm S D$, or geometric means $\mathrm{x} / \div$ (exponent of $S D$ of the log transformed variable) or for the ACCELEROMETER variables median (lower quartile, upper quartile) or \%.

${ }^{a}$ Logarithsm taken for comparing geometric means.

${ }^{b}$ Sedentary: $<100$ counts/min; Moderate or vigorous intensity activity: $\geq 10$ consecutive mins with > 1,952counts/min.

${ }^{\mathrm{c}}$ t-tests for continuous variables, $\chi^{2}$ test for categorical variables, Wilcoxon tests for ACCELEROMETER variables 


\section{Table 2}

Cardio-metabolic risk factors, means (SE) or geometric means $[\mathrm{SE}]^{\mathrm{a}}$, according to quartiles of time spent sedentary at baseline adjusted for the time the accelerometer was worn; means are adjusted for age, gender and recruitment centre; $P_{\text {trend }}$ values are adjusted for age, gender and recruitment centre and additionally for time spent in activities of moderate or vigorous intensity. The RISC Study

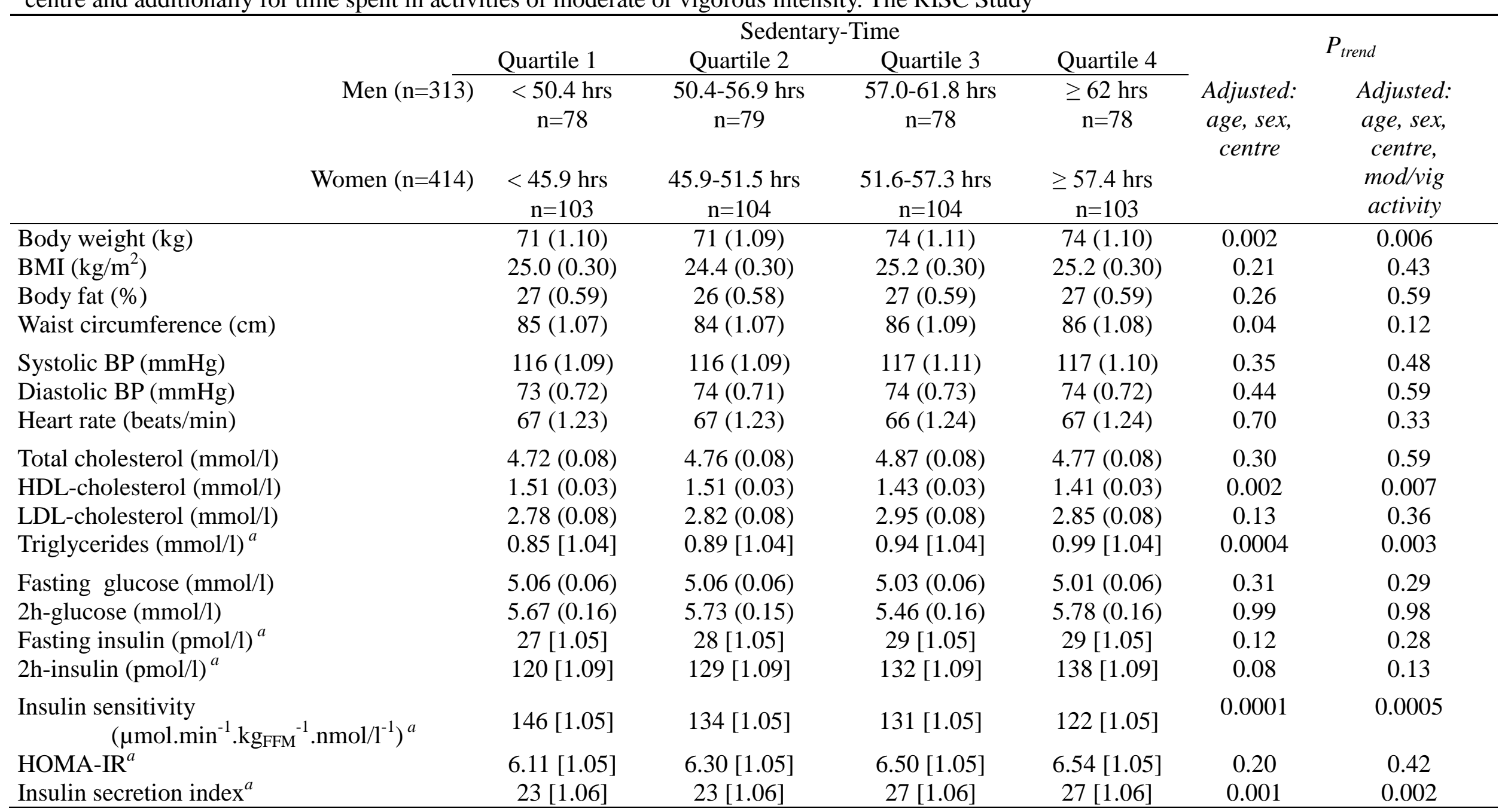

\footnotetext{
a geometric means $[\mathrm{SE}]$
} 
3-year change in

fasting glucose (mmol/l)

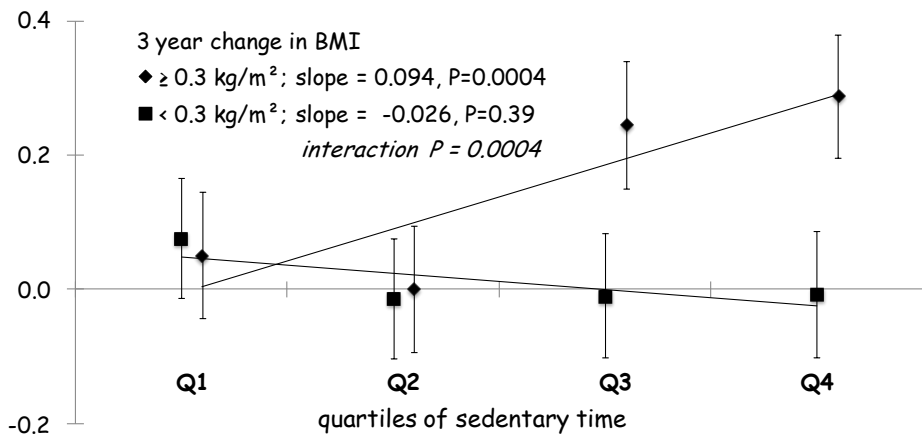

B

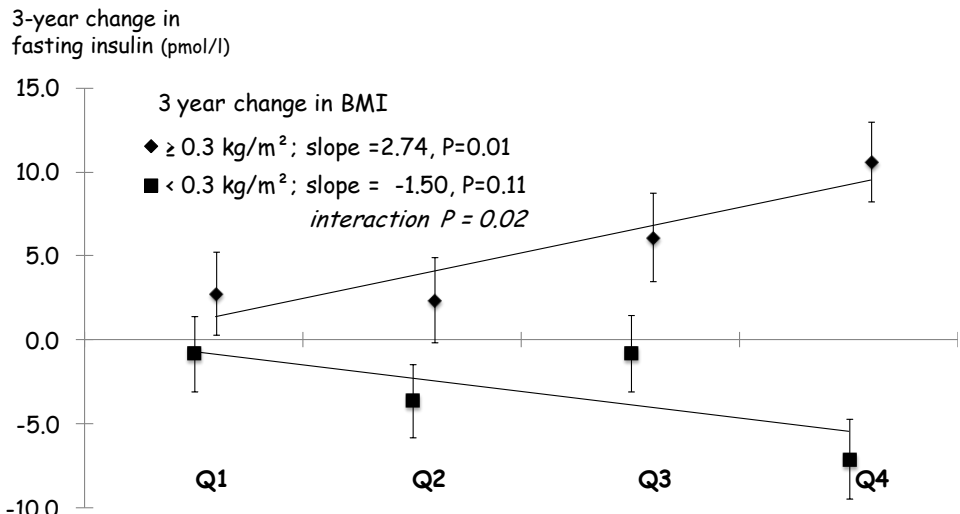

quartiles of sedentary time

3-year change in

HOMA-IR

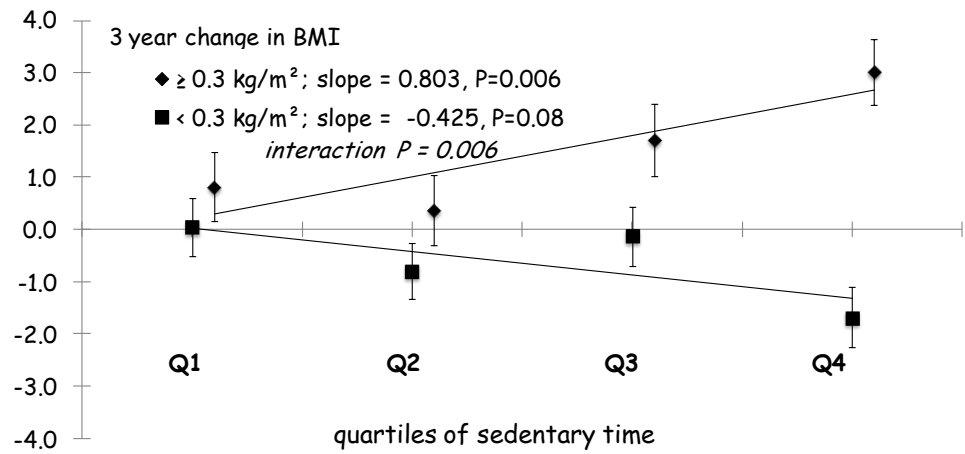


Supplementary Material 


\section{Supplementary Table 1}

Cardio-metabolic risk factors, means (SE) or geometric means [SE $]^{a}$, according to quartiles of time spent in activities of moderate or vigorous intensity at baseline, adjusted for the time the accelerometer was worn; means are adjusted for age and recruitment centre; $P_{\text {trend }}$ values are adjusted for age, gender, recruitment centre and additionally for BMI. The RISC Study

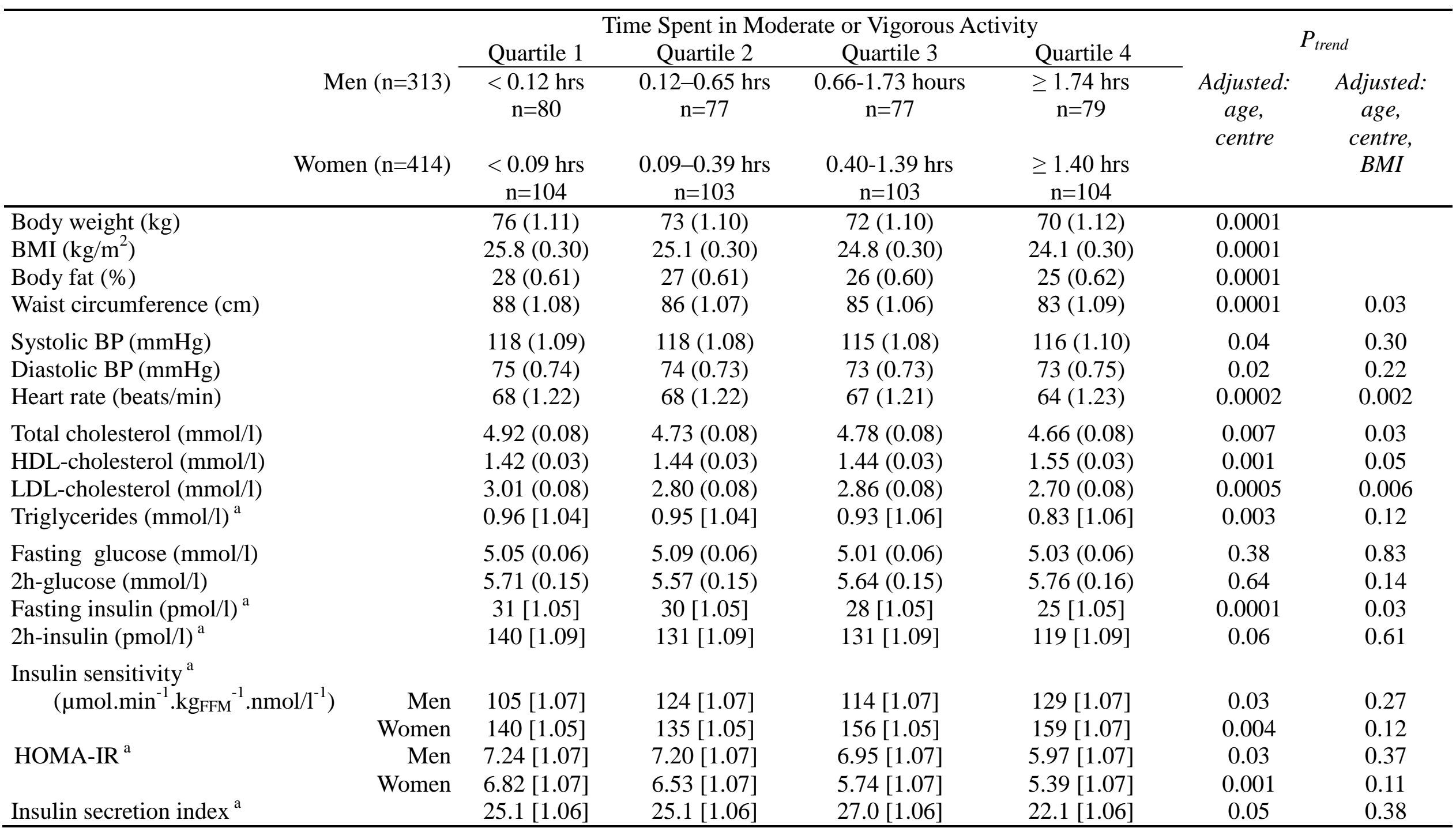

\footnotetext{
${ }^{a}$ geometric means $[\mathrm{SE}]$
} 
Supp Fig. 1 Mean (SE) of 3-year changes in (a) fasting glucose, (b) fasting insulin and (c) the HOMA-IR index according to baseline of time spent in moderate or vigorous activity, adjusted for age, gender and clinical recruitment centre, according to strata of change in BMI below and above the median change of $+0.3 \mathrm{~kg} / \mathrm{m}^{2}$. The RISC study

a

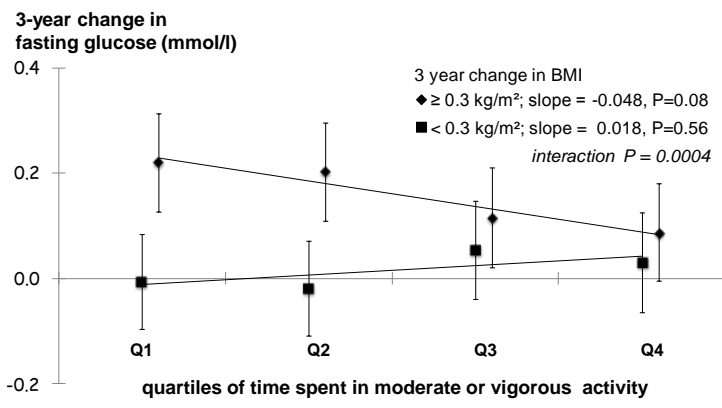

b

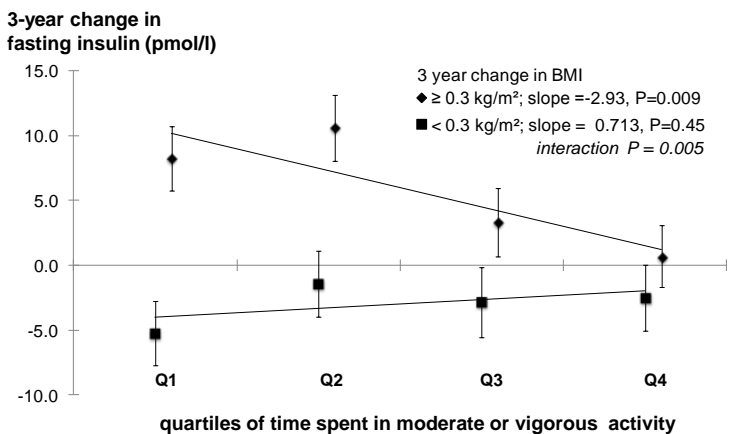

C

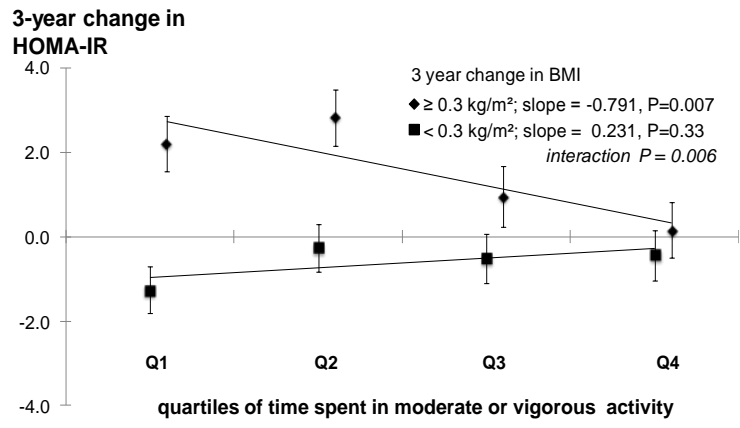




\section{RISC INVESTIGATORS}

\section{RISC recruiting centres}

Amsterdam, The Netherlands: RJ Heine, J Dekker, S de Rooij, G Nijpels, W Boorsma

Athens, Greece: A Mitrakou, S Tournis, K Kyriakopoulou, P Thomakos

Belgrade, Serbia: N Lalic, K Lalic, A Jotic, L Lukic, M Civcic

Dublin, Ireland: J Nolan, TP Yeow, M Murphy, C DeLong, G Neary, MP Colgan, M Hatunic

Frankfurt, Germany: T Konrad, H Böhles, S Fuellert, F Baer, H Zuchhold

Geneva, Switzerland: A Golay, E Harsch Bobbioni,V. Barthassat, V. Makoundou, TNO Lehmann, T Merminod

Glasgow, Scotland: JR Petrie (now Dundee), C Perry, F Neary, C MacDougall, K Shields, L Malcolm

Kuopio, Finland: M Laakso, U Salmenniemi, A Aura, R Raisanen, U Ruotsalainen, T Sistonen, M Laitinen, H Saloranta

London, England: SW Coppack, N McIntosh, J Ross, L Pettersson, P Khadobaksh

Lyon, France: M Laville, F. Bonnet (now Rennes), A Brac de la Perriere, C Louche-Pelissier, C Maitrepierre, J Peyrat, S Beltran, A Serusclat

Madrid, Spain: R. Gabriel, EM Sánchez, R. Carraro, A Friera, B. Novella

Malmö, Sweden (1): P Nilsson, M Persson, G Östling, (2): O Melander, P Burri

Milan, Italy: PM Piatti, LD Monti, E Setola, E Galluccio, F Minicucci, A Colleluori

Newcastle-upon-Tyne, England: M Walker, IM Ibrahim, M Jayapaul, D Carman, C Ryan, K Short, Y McGrady, D Richardson

Odense, Denmark: H Beck-Nielsen, P Staehr, K Hojlund, V Vestergaard, C Olsen, L Hansen

Perugia, Italy: GB Bolli, F Porcellati, C Fanelli, P Lucidi, F Calcinaro, A Saturni

Pisa, Italy: E Ferrannini, A Natali, E Muscelli, S Pinnola, M Kozakova, A Casolaro, BD Astiarraga

Rome, Italy: G Mingrone, C Guidone, A Favuzzi. P Di Rocco

Vienna, Austria: C Anderwald, M Bischof, M Promintzer, M Krebs, M Mandl, A Hofer, A Luger, W Waldhäusl, M Roden

Project Management Board: B Balkau (Villejuif, France), SW Coppack (London, England), JM Dekker (Amsterdam, The Netherlands), E Ferrannini (Pisa, Italy), A Golay (Geneva, Switzerland), A Mari (Padova, Italy), A Natali (Pisa, Italy), J Petrie (Dundee, Scotland), M Walker (Newcastle, England)

\section{Core laboratories and reading centres}

Lipids Dublin, Ireland: P Gaffney, J Nolan, G Boran

Hormones Odense, Denmark: C Olsen, L Hansen, H Beck-Nielsen

Albumin:creatinine Amsterdam, The Netherlands: A Kok, J Dekker

Genetics Newcastle-upon-Tyne, England: S Patel, M Walker

Stable isotope laboratory Pisa, Italy: A Gastaldelli, D Ciociaro

Adiponectin, CRP, MBL Odense, Denmark: Allan Flyvbjerg

Ultrasound reading centre Pisa, Italy: $M$ Kozakova

ECG reading, Villejuif, France: MT Guillanneuf

Actigraph, Villejuif, France: B Balkau, L Mhamdi

Data Management Villejuif, France, Padova, and Pisa, Italy: B Balkau, A Mari, L Mhamdi, L Landucci, S Hills, L Mota

Mathematical modelling and website management Padova, Italy: A Mari, G Pacini, C Cavaggion, A Tura

Coordinating office: Pisa, Italy: SA Hills, L Landucci, L Mota

Further information on the RISC Study and participating centres can be found on www.egir.org. 